\title{
EXPERIÊNCIAS COM A DIETILAMINA DO ÁCIDO LISÉRGICO (LSD 25)
}

\author{
Paulo Luiz Vianna Guedes *
}

O presente trabalho se baseia em cinco experiências com LSD 25 feitas em três pacientes: um caso grave de neurose histérica (duas aplicaçōes), um caso de esquizofrenia paranóide (uma aplicação) e um de neurose de caráter - caráter histérico (duas aplicações). Sua finalidade: verificação da ação desta substância sob os aspectos psicológicos e estudo de suas possibilidades como auxiliar da psicoterapia.

\section{MÉTODO}

Oscilaram as doses usadas entre 7 comprimidos (de $0,025 \mathrm{mg}$ cada um) ministrados em duas tomadas - a primeira de 4 comprimidos e a segunda de $3-\mathrm{e}$ 13 comprimidos em 4 tomadas - as primeira, segunda e terceira de 4 comprimidos e a quarta de 1 . E interessante salientar que, coincidindo com a opinião generalizada sôbre o tema, o paciente que necessitou maior dose foi aquêle que apresentava sintomatologia psicótica (delírio de referência). As doses intermediárias foram, respectivamente, de 8 comprimidos (4 em 4), 8 comprimidos (duas doses de 3 e duas de 1) e 9 comprimidos $(4,3,2)$.

Após verificação de possiveis lesões renais, hepáticas e cardiovasculares - principais contra-indicaçōes ao uso da substância — foi o LSD 25 ministrado por via oral estando o paciente em jejum.

A duração das experiências oscilou entre 7 e $8 \frac{1}{2}$ horas. O período francamente psicótico sobreveio, em regra, entre a $4^{\mathrm{a}}$ e $5^{4}$ hora após a primeira dose, durante mais ou menos duas horas para, então, entrar em declinio.

A fim de apressar a interrupção da ação do LSD 25 foi usada a cloropromazina por via oral, sendo a intramuscular reservada para aquêles casos em que ocorreram vômitos. Algumas vêzes lançou-se mão do Amital sódico por via oral. $O$ quadro abaixo dará uma idéia global das doses, tanto de LSD 25 quanto dos medicamentos usados para interromper sua ação:

\begin{tabular}{ccccc} 
& & \multicolumn{2}{c}{ Cloropromazina } & Amital sódico \\
Ėxperiência & LSD 25 & oral & muscular & oral \\
1 & $200 \mathrm{~g}$ & $50 \mathrm{mg}$ & - & 0,40 \\
2 & $200 \mathrm{~g}$ & $25 \mathrm{mg}$ & - & 0,20 \\
3 & $325 \mathrm{~g}$ & $50 \mathrm{mg}$ & - & 0,40 \\
4 & $225 \mathrm{~g}$ & - & $25 \mathrm{mg}$ & 0,20 \\
5 & $175 \mathrm{~g}$ & - & $25 \mathrm{mg}$ & -
\end{tabular}

* Docente Livre de Clínica Psiquiátrica da Fac. de Med. de Pôrto Alegre, Rio Grande do Sul.

Nota do autor - Agradeço aos Drs. Ellis Busnello, Enio Arnt, Moisés Roitman e Paulo Machado que, como observadores, prestaram inestimável colaboração à realização destas experiências. 
Conforme se vê, não há relação entre a dose de LSD 25 e a quantidade necessária de cloropromazina (ou Amital) para neutralizá-la. E que a quantidade destas últimas substâncias é inversamente proporcional ao tempo em que é usada, isto é, quanto mais tardiamente são elas ingeridas (portanto já quando declina a asão do LSD 25) menor será a dose necessária.

\section{RESULTADOS}

Entre os sintomas expressos no plano somático, os mais comumente verificados foram: sonolência, sensação de tontura, estado vertiginoso, rubor da face, face vultosa, sudorese de intensidade variável, sensação de pêso na cabeca, no ventre ou nos membros, dificuldade ou mesmo impossibilidade de movimentos nos membros superiores e inferiores, "dormência" nos membros, na face, nos lábios ou no corpo todo, cefaléias, dores na nuca, astenia mais ou menos acentuada. Embora tenha sido frequientemente assinalado estado nauseoso, vómitos só ccorreram em duas experiências, realizadas no mesmo paciente. Aliás, êste caso apresentou, no fim de uma delas, após a administração de uma ampôla de $25 \mathrm{mg}$ de cloropromazina, acentuado estado lipotímico que cedeu ràpidamente.

Quanto aos fenômenos expressos no plano psicológico são dignos de nota:

Perda de orientação quanto ao lugar - Em 4 das 5 experiências apresentou-se franca ou relativa desorientação quanto ao lugar, desorientação que foi vivida sob maior ou menor angústia.

Perda de orientacão quanto ao tempo - Comumente, na vivência dos pacientes, o tempo passa muito mais ràpidamente do que o tempo cronológico e, assim é comum nāo acreditarem nas informaçōes que constantemente pedem sôbre a horáa. Casos há em que a vivência é de enorme vagarosidade quanto ao passar do tempo.

Modificacões do esquema corporal — A negação de partes do corpo (não ter braços, não ter mãos), ou do corpo todo ("eu não existo") foi assinalada algumas vêzes, bem como a sensação de estar diminuindo de tamanho e de se tornar "muito pequeno", "uma criança", conforme expressão dos pacientes. Um paciente perdeu, durante algum tempo, a noção da posição espacial do corpo e, por isto, queixava-se, a todo o momento, de não saber para que lado estava a sua cabeça ou para que lado seu corpo estava virando.

Perturbações da experiência do ego - Embora nunca encontrássemos perda total da orientação quanto à pessoa, manifestaram-se comumente, em intensidade variável, francos sinais de despersonalização. Interessantes foram os casos em que paulatinamente se esfumavam os limites entre realidade interna e externa. Assim, um dos pacientes não podia se decidir quanto à origem do estimulo sensorial a oue estava submetido: tratava-se de situação em que, estimulado auditivamente por um rádio que, no momento, transmitia programa musical, o paciente angustiado interrogava, repetidas vêzes, se o que ouvia estava "de fato" sendo executado fora de si ou se seria "impressão" sua, que talvez estivesse apenas imaginando aquêle trecho musical, e, apesar dos esforços feitos, nāo conseguiu - até que informado - orientar-se quanto à situação, mostrando o quanto lhe era difícil, impossivel mesmo, naquele estado, a distinção entre objeto interno e externo.

Este mesmo paciente, quando do momento de intensidade máxima da ação do medicamento, foi prêsa de intensa ansiedade com sensaçāo de despersonalizacāo que expressava queixando-se de "não existir" ou de "estar sonhando", vivência que só pôde corrigir após haver, várias vêzes, tocado o médico e se certificado da realidade da existência dêste. Então pôde tranqüilizar-se, pois era a realidade da existência do objeto que the trazia a certeza da própria existêneia. Em outro caso ocorreram, na fase do inicio da maior açāo do LSD 25, intensissimas identificações projetivas e introjetivas tão vivas e reais quanto as encontráveis nos grandes estados psicóticos: o paciente, tomado de ansiedade, começou a rir compulsi- 
vamente, pois o médico estaria doente e dever-se-ia submeter à experiência para ser analisado por êle que, no momento, sentia-se médico. Interessante é que podia julgar da irrealidade da sua vivência ao mesmo tempo em que convictamente acreditava nela, expressando assim, além do duplo jôgo de identificações projetivas (atributos do paciente eram postos no médico) e introjetivas (o enfêrmo incorporava as qualidades do terapeuta), tipica dissociação do ego em que uma parte sofria a ação da droga, enquanto que outra, sem perder o contato com a realidade, podia julgar as modificaçōes apresentadas pela primeira.

Memória - A percepção dos sucessos ocorridos se manteve, como lembrança, mesmo após o término da experiência e, assim, foi possível, nos dias sucessivos, obter dos pacientes relatos muito fiéis das vivências experimentadas durante a ação lisérgica.

Alterações da sensopercepção - No que se refere ao aspecto visual, verdadeiro fenômeno alucinatório não nos foi dado observar, tendo sido, em troca, frequientes as manifestações ilusórias. Em um caso ocorreu típica alucinaçāo negativa. Digna de nota foi a perturbação de outro enfêrmo que, durante o tempo de máxima ação do medicamento, via a imagem do médico multiplicada várias vêzes e colocada, cada uma delas, em vários pontos da sala. Além disto, foram comuns as alteracões do contôrno dos objetos que apareciam mais nitidos com côres mais vivas, demonstrando o paciente estranheza frente aos mesmos ou, ainda, em um caso, perturbação da exata noção da distância entre a própria pessoa e o ambiente externo.

Quanto ao ouvido, o sintoma mais chamativo, foi uma alucinação negativa que ocorreu em um caso. No que se refere ao sentido do gôsto, a regra é sua supressão: os alimentos tornam-se insipidos, o cigarro é "sem gôsto" ou, como alteração qualitativa, apresenta gôsto "diferente". Pseudo-alucinações gustativas e olfativas apresentou um paciente que sentia típico gôsto e cheiro de camarão.

No plano da sensibilidade superficial (táctil, térmica e dolorosa) foram comuns as sensaçōes de formigamento, de dormência, as sensações de frio e calor, e zonas de anestesia.

Alterações da esfera afetiva - Manifestaçōes de ansiedade mais ou menos intensas (às vêzes paroxísticas) são a regra. O fato de suas primeiras expressōes ocorrerem antes da ingestāo da droga, prova não dependerem elas da ação do medicamento, mas evidenciarem a reação individual ante a situação, vivida sempre em têrmos paranóides. Além da ansiedade, em dois casos, houve nitido quadro do tipo maniaco (um dêles com abundantes idéias pseudo-delirantes de grandeza); em outra experiência ocorreram intensas manifestações depressivas, com auto-acusacões, chôro e desespêro. Acentuado, na totalidade dos casos, foi o fenômeno da ambivalência. Neste sentido, um paciente percebia claramente duas ordens de idéias absolutamente antagónicas; assim, por exemplo, dizia gostar muito do médico, ao mesmo tempo que, "na outra idéia", tinha sentimentos agressivos contra o mesno $e$ isto sem que um sentimento interferisse sôbre o outro.

Sintoma encontrado com freqüencia foi o autismo que, em um dos casos, assumiu grandes proporçōes.

Transtornos associativos e do pensamento - Um caso, no momento máximo da ação do medicamento, apresentou franca "fuga de idéias", com aceleração do tempo do pensamento, associações superficiais e por assonância; outro paciente apresentou intenso e longo "mutismo".

Delírios ou idéias delirantes verdadeiras, isto é, com franca aceitação pelo juizo de realidade, não foram verificados no curso das experiências, senão por breve espaço de tempo. Em compensação, frequientes foram as idéias pseudo-delirantes. No mesmo sentido foram assinaladas algumas vêzes "interpretações delirantes, ou melhor, "modificações da significação do objeto" coexistentes ao lado de compreensão exata (dupla orientação significativa). 


\section{COMENTARIOS}

Como se vê, além de modificações várias no plano somático, a ingestão de ácido lisérgico, nas doses indicadas, provoca abundante sintomatologia psicológica, na qual ressaltam as modificações do ego, franca regressão com afloramento de mecanismos arcáicos: dissociação, identificações projetivas e introjetivas, negação). Interessante é o fato de que, mesmo durante o tempo em que está sob a ação da droga, o paciente conserva uma parte do ego que, com justeza, pode observar e descrever as modificaçōes experimentadas por sua personalidade. Tal fato e a possibilidade de conservação, nos dias subseqüentes, da lembrança dos sucessos vividos, permitem obter, tempos depois, relatos muito fiéis da experiência.

Além dos aspectos acima aludicios, o que torna a experiência grandemente valiosa - e, talvez, aí residam as melhores propriedades da droga como auxiliar da psicoterapia - é o aparecimento, sob forma intensamente dramática, de situações e fantasias conflituosas infantis. Tal material surge, não como recordação histórica de algo passado, mas é repetido transferencialmente, sob grande intensidade afetiva, mostrando quanto êle presente na atualidade do enfêrmo - é capaz de modelar sua conduta, dirigir seus sentimentos e interferir no seu contato com a realidade subjetiva e objetiva.

Neste sentido é ilustrativo o caso de um paciente cuja neurose - desencadeada após rompimento com a noiva que lhe fôra infiel -- repetia situação neurótica infantil sobrevinda, aos quatro anos de idade, quando do nascimento de sua irmā mais nova. Naquela época sentia-se, como na atualidade, triste, "mal humorado", experimentando raiva intensa e permanente, chorando muito "por nada"; sem falar com ninguém e "sem achar graça nas coisas", andava sempre com mêdo dos outros que, parecia, queriam-lhe mal; por isto passava os dias quieto, sem bricar e sem estabelecer contato com ninguém; quando, à tarde, êle com os irmãos mais velhos iam à roça levar café para os pais que lá se encontravam com a irmãzinha recém-nascida, dava-lhe "aquela raiva", "aquela má vontade" e, atirava-se ao chão, de bruços, negando-se a cooperar; ali ficava, "emburrado", "sem dar palavra com ninguém", opondo-se a prosseguir caminho, até que os irmãos o pegavam, à fôrça, e o obrigavam a seguir, o que muito o encolerizava.

Ingerida a droga - experiência a que se submeteu de boa vontade suas principais manifestações consistiram na repetição dramática daquela situação pretérita. Assim, deitou-se de bruços, negando-se a cooperar, permanecendo mudo, mal humorado, mostrando grande irritação quando solicitado.

Sentia-se pequeno, "uma criança sem fôrças" e acusava o médico de não lhe querer bem. Visìvelmente enciumado com o observador - acompanhante do terapeuta - repetia transferencialmente, em relação àquele, sua velha hostilidade face à irmã. Com o médico reproduzia antigo esque- 
ma afetivo relacionado à mãe e, assim, tornou-se exclusivista, exigindo dêste tôda a atenção, mostrando-se muito irritado quando dispensava êle qualquer consideração ao assistente (irmã). Acusava-o de não gostar tanto dêle quanto gostava antes, mas de ter agora "se passado todo" para o observador. Exigia-lhe constantemente cigarros e mais que isto - numa dramatização da amamentação - obrigava-o a que, sentado a seu lado, introduzisse em sua bôca e dela retirasse os cigarros que fumava em boa aproximação afetiva. Imediatamente - e sempre relacionado ao ciúme do observador - encolerizava-se e recusava-se a prosseguir, pois desconfiava das intenções do médico que, segundo êle, raivoso, poderia querer prejudicá-lo. Assim expressava o quanto a projeção de sua hostilidade tornava perigosos e ameaçadores os objetos externos e, sobretudo, o quanto seu esquema afetivo infantil relacionado à mãe interferia na atualidade, em seu contato com a realidade objetal.

Da mesma forma comportaram-se, neste particular, os demais pacientes

Esta repetição transferencial das vivências infantis, vivida e, ao mesmo tempo, assistida por uma parte do ego, amplia enormemente - ao menos durante o curso da experiência - o "insight" do enfêrmo que é capaz de captar seu material reprimido, sentir sua realidade e vivenciá-lo como algo existente dentro de si e, ainda, ativo em sua atualidade. Daí a facilidade e grau de convicção com que, comumente, apreendem os pacientes as interpretações do terapeuta. Assim, um paciente que precedentemente fôra submetido a longo tratamento analítico, durante a experiência lisérgica repetia situações já conhecidas através de sua psicoterapia, mas a intensidade com que as experimentava e o grau de convicção na realidade de seus conflitos e na justeza das interpretações do médico emprestavam às últimas caráter de verdadeira "revelação". À medida, porémı, que diminuía a ação da droga, e o conseqüente grau de regressão, assistia-se à restruturação das defesas ióicas. Tais defesas, no entanto, não impediram que, em subseqüentes sessōes, fora da situação lisérgica, continuasse a ser elaborado o material nela surgido e muitas vêzes - e isto meses depois - no momento de mais intensa resistência à aceitação de determinada interpretação foi sua associação a lembranças das situações correspondentes ocorridas na experiência com LSD 25 que pôde abalar sua atitude de rejeição.

Em um dos casos, porém, a intensidade defensiva era tão acentuada que nem a ação da droga facilitou sua diminuição. Tratava-se de pessoa psicótica que, graças à sua estrutura paranóide, necessitava manter segrêdo sôbre determinado sucesso de sua vida infantil (experiência homossexual a que sua fantasia emprestava caráter terrorífico). Ingerido o LSD 25 - a que, aparentemente, se submeteu de boa vontade - embora durante todo o tempo ocorresse-lhe a lembrança do aludido episódio, conforme confessou um ano mais tarde, pôde continuar mantendo silêncio sôbre o mesmo. À medida que aumentou a ação do medicamento, entrou em franco e intenso período de desadaptação à realidade, mas êste se caracterizou pela sucessão de fases distintas, nas quais, graças a diferentes mecanismos, conseguiu 
continuar ocultando o que desejava. Embora, através da atividade defensiva, se pudesse entrever nitidamente o conflito que o paciente se esforçava for ocultar (graças à projeção dêste no terapeuta), seu temor paranóide em relação a êste último o impedia de aceitar a justeza de suas interpretações e, embora a experiência constituisse repetição dos conflitos passados, as defesas paranóides e negação sistemática não só das interpretações mas de suas próprias ocorrências internas tornaram ineficaz, no sentido de ampliação do "insight", tal experimento; em sucessivas sessōes fora do uso da droga, pôde-se evidenciar não ter trazido vantagem a administração do ácido lisérgico quanto à melhor compreensão e vivência dos conflitos inconscientes. Das 5 observações, esta foi a única em que a droga não trouxe tal vantagem. Em tôdas as outras, puderam os enfermos - pelo menos durante a experiência - vivenciar plenamente seus problemas e, ao mesmo tempo, seu maior "insight" trazia-lhes boa compreensão da ação que os mesmos desempenhavam em sua vida atual.

Eis os principais dados que nos foram dados observar no curso das experiências com a dietilamida do ácido lisérgico. A concordância com o relato de grande parte dos autores realça a validade das observações registradas neste trabalho, apesar do reduzido número de casos apresentados. Ressaltamos a propriedade que tem o LSD 25 de provocar intensa regressão da personalidade, regressão que pode ser utilizada para tratamento psicoterápico que vise ajudar o paciente a compreender suas dificuldades íntimas responsáveis pelos quadros apresentados. A intensidade das vivências que acompanham o aparecimento do material conflituoso, a conservação de uma parte do ego capaz de, no decorrer da experiência, assisti-lo e julgá-lo (propriedade da qual deriva franca ampliação do "insight") e a possibilidade que traz ao paciente de conservar a lembrança de tais sucessos (o que permite poder ser tal material elaborado em ulteriores sessões, fora da ação lisérgica), tornam o LSD 25 superior, como auxiliar da psicoterapia, a outras substâncias cujo emprêgo tem sido tentado com a mesma finalidade. Por outro lado, sendo o material fornecido pelo paciente, não um material direto mas derivado dos conflitos inconscientes e, como tal, deformado de acôrdo com as leis do processo primário, torna-se necessário ao médico estar francamente familiarizado com os dinamismos e conseqüente interpretação das manifestações inconscientes. Em outras palavras, só nas mãos de médico psicanalista pode, a nosso ver, ser de real utilidade o uso do LSD 25 como auxiliar do tratamento psicoterápico.

\section{RESUMO}

São relatados os resultados de 5 experiências realizadas em 3 pacientes corn LSD 25, sendo salientadas as propriedades terapêuticas dêste medicamento como auxiliar da psicoterapia. Entre outras, são ressaltadas como principais qualidades: a) ação regressiva sôbre o ego que facilita o apa- 
recimento, sob forte carga afetiva, dos conflitos internos na transferência; b) ação não uniforme sôbre o ego, poupando umas partes que, assim, não só assistem, mas podem, durante a experiência, analisar o material surgido; c) conservação da memória que permite em dias ulteriores e fora da ação lisérgica, a análise das vivências ocorridas na experiência. O método só terá tôda sua utilidade, na opinião do autor, em mãos de médico psicanalista capacitado a lidar com material derivado do inconsciente.

\section{SUMMARY \\ Experiences with diethilamid of lysergic acid.}

The results of 5 experiences with the LSD 25 made with three patients are reported, pointing out especially the therapeutic properties of this drug as an aid in psychotherapy. Special consideration is given to the following properties: a) regressive action upon ego that facilitates the appearing of internal conflicts under a strong emotive charge in transfer; b) nonuniform action upon ego keeping out some parts that in this way not only assist but can also, during the experience, analyse the obtained material; c) keeping in the patient's memory of what he lived during the experience, allowing its analysis later on and out of lysergic action. In the author's opinion this method will have its full utility only when employed by a psychoanalyst who is able to work with material obtained from unconscious.

Rua Barāo de Santo Ângelo, 152 - Pôrto Alegre, Rio Grande lo Sul. 